\title{
Novas Diretrizes Curriculares Nacionais para a Formação Inicial de Professores para a Educação Básica: avanços ou retrocessos?
}

\author{
New National Curriculum Guidelines for Initial Teacher Education for \\ Basic Education: advances or setbacks?
}
New National Curriculum Guidelines for Initial Teacher Education for Basic Education: advances or setbacks?

Nelson Luiz Reyes Marques ${ }^{1}$; Gilberto Orengo ${ }^{2}$; Maykon Gonçalves Müller ${ }^{3}$; Cristiano da Silva Buss"; Marcos André Betemps Vaz da Silva ${ }^{5}$

\begin{abstract}
RESUMO
O artigo contextualiza a política de formação de professores da Educação Básica no Brasil fazendo uma análise das Diretrizes Curriculares Nacionais para a formação inicial e continuada dos profissionais da educação de 2001 até 2019, tendo como foco principal a discussão do entendimento de prática como componente curricular nesses documentos. Apresentamos uma análise do tempo dedicado à prática ao longo dos Cursos, bem como dos deslocamentos do conceito de Prática nos documentos. É possível perceber uma variação entre posturas mais teóricas até aquelas mais voltadas para a aplicação dos conhecimentos. Por último, é descrito que as Novas Diretrizes Curriculares Nacionais para a Formação Inicial de Professores da Educação Básica podem prejudicar a constituição de futuros docentes reflexivos, autônomos e com abrangência nos mais diferentes saberes profissionais, disciplinares, curriculares e experienciais.
\end{abstract}

Palavras-chave: Formação de Professores; Estágio; Prática como Componente Curricular.

\section{ABSTRACT}

The article contextualizes the basic education teacher education policy in Brazil by analyzing the National Curriculum Guidelines for the initial and continuing training of education professionals from 2001 to 2019, with the main focus on the discussion of the understanding of practice as a curricular component in these documents. We present an analysis of the time dedicated to practice throughout the Courses, as well as the shifts in the concept of Practice in the documents. It is possible to perceive a variation between more theoretical stances to those more focused on the application of knowledge. Finally, it is described that the New National Curriculum Guidelines for the Initial Formation of Teachers of Basic Education can harm the constitution of future reflective,

\footnotetext{
${ }^{1}$ Professor e Pesquisador do Programa de Pós-graduação em Ciências e Tecnologias na Educação (PPGCITED) do Campus Pelotas Visconde da Graça do Instituto Federal Su-rio-grandense (IFSUL), Pelotas, RS, Brasil. E-mail: nelsonmarques@ifsul.edu.br

2 Professor e Pesquisador do Programa de Pós-graduação em Ensino de Ciências e Matemática (PPGECIMAT) da Universidade Franciscana (UFN), Santa Maria, RS, Brasil. E-mail: g.orengo@gmail.com

${ }^{3}$ Professor e Pesquisador do Programa de Pós-graduação em Ciências e Tecnologias na Educação (PPGCITED) do Campus Pelotas Visconde da Graça do Instituto Federal Su-rio-grandense (IFSUL), Pelotas, RS, Brasil. E-mail: maykon.ifsul@gmail.com

${ }^{4}$ Professor e Pesquisador do Programa de Pós-graduação em Ciências e Tecnologias na Educação (PPGCITED) do Campus Pelotas Visconde da Graça do Instituto Federal Su-rio-grandense (IFSUL), Pelotas, RS, Brasil. E-mail: cristianodasilvabuss@gmail.com

${ }^{5}$ Professor e Pesquisador do Programa de Pós-graduação em Ciências e Tecnologias na Educação (PPGCITED) do Campus Pelotas Visconde da Graça do Instituto Federal Su-rio-grandense (IFSUL), Pelotas, RS, Brasil. E-mail: marcos.betemps@gmail.com
} 
autonomous teachers with scope in the most different professional, disciplinary, curricular and experiential knowledge.

Keywords: Teacher education; Phase; Practice as a Curricular Component.

\section{RESUMEN}

El artículo contextualiza la política de formación docente de educación básica en Brasil mediante el análisis de los Lineamientos Curriculares Nacionales para la formación inicial y continua de los profesionales de la educación de 2001 a 2019, con el foco principal en la discusión de la comprensión de la práctica como componente curricular en estos documentos. Presentamos un análisis del tiempo dedicado a la práctica a lo largo de los Cursos, así como los desplazamientos del concepto de Práctica en los documentos. Es posible percibir una variación entre posturas más teóricas a aquellas más enfocadas a la aplicación del conocimiento. Finalmente, se describe que los Nuevos Lineamientos Curriculares Nacionales para la Formación Inicial de Docentes de Educación Básica pueden perjudicar la constitución de futuros docentes reflexivos, autónomos y con alcance en los más diversos saberes profesionales, disciplinarios, curriculares y vivenciales.

Palabras clave: Formación del profesorado; Prácticas; Práctica como componente curricular.

\section{INTRODUÇÃO}

O primeiro documento que apresenta informações sobre a concepção de prática, presente nas Diretrizes Curriculares Nacionais (DCN) de 2002, é o Parecer CNE/CP nº 9, de 8 de maio de 2001 (PEREIRA e MOHR, 2017). De acordo com esse parecer, nos cursos de formação de professores, a concepção dominante até aquele momento segmenta o curso em dois polos isolados entre si: um caracterizado pelo trabalho na sala de aula e o outro, caracterizado pelas atividades de estágio. 0 primeiro polo supervaloriza os conhecimentos teóricos, acadêmicos, desprezando as práticas como importante fonte de desenvolvimento de conteúdos da formação. Existe, assim, uma visão aplicacionista das teorias. O segundo polo supervaloriza o fazer pedagógico, desprezando a dimensão teórica dos conhecimentos como instrumento de seleção e análise contextual das práticas. Neste caso, há uma visão ativista da prática, onde são ministrados cursos de teorias prescritivas e analíticas, deixando para os estágios o momento de colocar esses conhecimentos em ação. Nesse sentido, o Parecer CNE/CP 9/2001 passa a considerar a concepção de prática mais como uma componente curricular e isso implica em vê-la como uma dimensão do conhecimento que tanto está presente nos cursos de formação, nos momentos em que se trabalha na reflexão sobre a atividade profissional, como durante o estágio, nos momentos em que se exercita a atividade profissional.

A Resolução CNE/CP no 1, de 18 de fevereiro de 2002, estabelece que a prática docente na matriz curricular não poderá ficar reduzida a um espaço isolado, que a restrinja ao estágio, desarticulado do restante do curso. Ou seja, deverá estar presente durante o decorrer do curso de Licenciatura e permear toda trajetória acadêmica do professor. Estabelece que a dimensão prática esteja no interior das áreas ou das disciplinas que constituírem os componentes curriculares de formação, e não apenas nas disciplinas pedagógicas. Para Pereira e Mohr (2017) essa concepção de prática vê o professor como um pesquisador, que reflete sobre a sua prática e, segundo Souza Neto e Silva (2014), essa dimensão prática não poderá ficar restrita às disciplinas pedagógicas, cabendo ressaltar que a coordenação da dimensão prática transcenderá o estágio. Terá como finalidade a articulação das diferentes práticas, numa perspectiva interdisciplinar, pois assim a ênfase estará nos procedimentos de observação e reflexão, no registro das observações realizadas e na resolução de situaçõesproblema. 
Pimenta e Lima (2019) destacam a importância da experiência, de sua reflexão e dos saberes provenientes dessa experiência na profissão ao desenvolverem suas práticas. Acreditam que a formação deve ser baseada na epistemologia da prática, ou seja, na valorização da prática profissional como momento de construção de conhecimento por meio da reflexão, análise e problematização dessa prática. Tardif (2000) define a epistemologia da prática profissional como o estudo do conjunto dos saberes utilizados realmente pelos profissionais em seu espaço de trabalho cotidiano para desempenhar todas as suas tarefas. $\mathrm{O}$ autor destaca que:

[...] A finalidade de uma epistemologia da prática profissional é revelar esses saberes, compreender como são integrados concretamente nas tarefas dos profissionais e como estes os incorporam, produzem, utilizam, aplicam e transformam em função dos limites e dos recursos inerentes às suas atividades de trabalho. Ela também visa compreender a natureza desses saberes, assim como o papel que desempenham tanto no processo de trabalho docente quanto em relação à identidade profissional dos professores (TARDIF, 2000, p. 11).

O Parecer CNE/CP No: 22/2019 justifica que a necessidade de revisão e atualização dos documentos tem como objetivo atender a legislação vigente, a começar pela própria Lei no 9.394, de 20 de dezembro de 1996, de Diretrizes e Bases da Educação Nacional (LDB), a qual prevê a adequação curricular dos cursos, programas ou ações para a formação inicial e continuada de professores. 0 estabelecido na Base Nacional Comum Curricular (BNCC), quando, no $\S 8^{\circ}$ do seu art. 62, incluído pela Lei $n^{\circ} 13.415$, de 16 de fevereiro de 2017, dispõe que os currículos dos cursos da formação de docentes terão por referência a BNCC. O objetivo do nosso trabalho é fazer um resgate histórico das diretrizes anteriores e comparar o conceito de prática discutidos nesses documentos.

\section{POLÍtICAS PARA A FORMAÇÃO DE PROFESSORES NO BRASIL: ANÁLISE HISTÓRICA}

A Resolução CNE/CP no 2, de 19 de fevereiro de 2002, que institui a carga horária mínima obrigatória para as Licenciaturas, afirma que nos cursos de Formação de Professores da Educação Básica, em nível superior, em curso de Licenciatura, de graduação plena, tal carga será efetivada mediante a integralização de, no mínimo, 2800 (duas mil e oitocentas) horas, nas quais a articulação teoriaprática garante, nos termos dos seus projetos pedagógicos, as seguintes dimensões dos componentes comuns:

I - 400 (quatrocentas) horas de prática como componente curricular, vivenciadas ao longo do curso;

II - 400 (quatrocentas) horas de estágio curricular supervisionado a partir do início da segunda metade do curso;

III - 1800 (mil e oitocentas horas) para os conteúdos curriculares de natureza científico-cultural;

IV - 200 (duzentas) horas para outras formas de atividades acadêmico-científico-culturais.

É perceptível a análise que Pereira e Mohr (2017) fazem alertando que a dimensão da prática ocupa mais de um terço do mínimo de 2.800 horas destinadas à formação de professores, o que ocasiona diminuição do tempo destinado aos conteúdos curriculares de natureza científico-cultural. Foi nesse contexto, de valorização da escola básica e da prática docente como lugares de produção de conhecimento, que a prática como componente curricular (PCC) foi instituída como uma das disciplinas obrigatórias para formação docente (PERREIRA; MOHR, 2017). 
Para o Parecer CNE/CP 28/2001, que dá nova redação ao Parecer CNE/CP 21/2001, a prática na formação de professores não é uma cópia da teoria e nem esta é um reflexo daquela. Ainda segundo o Parecer CNE/CP 28/2001,

[...] a prática é o próprio modo como as coisas vão sendo feitas, cujo conteúdo é atravessado por uma teoria. Assim a realidade é um movimento constituído pela prática e pela teoria como momentos de um dever mais amplo, consistindo a prática no momento pelo qual se busca fazer algo, produzir alguma coisa e que a teoria procura conceituar, significar e com isto administrar o campo e o sentido desta atuação (CNE/CP 28/2001, p. 9).

O documento ressalta que é fundamental haver tempo e espaço para a PCC desde o início do curso e que haja uma supervisão da instituição formadora como forma de apoio até mesmo com o objetivo de uma avaliação de qualidade.

Para Souza Neto e Silva (2014) as 400 horas da PCC não podem e nem devem ser vistas como uma estratégia para buscar equilíbrio na relação teoria-prática nas disciplinas, mas devem ser pensadas na perspectiva interdisciplinar, buscando uma prática que produza algo no âmbito do ensino e auxilie na formação da identidade do professor como educador.

Já o Parecer CNE/CES no 15, de 2 de fevereiro de 2005, que foi solicitado pela Universidade Estadual do Sudoeste da Bahia (UESB) para esclarecer a Resoluções CNE/CP 1 e 2/ 2002 sobre a diferença entre a prática de ensino e a PCC, alega que a PCC é constituída por atividades formativas que proporcionam experiências de aplicação de conhecimentos ou de desenvolvimento de procedimentos próprios ao exercício da docência. Essas atividades devem colocar em uso as competências e habilidades adquiridas nas diversas atividades que compõe o currículo do curso. Já a prática de ensino (estágios supervisionados) constitui-se de atividades de formação realizadas sob a supervisão de docentes da instituição formadora e da escola, em que o estudante experimenta situações reais de exercício profissional. Ela deve consolidar e articular as competências e habilidades desenvolvidas.

No ano de 2015 foram homologados dois documentos, o Parecer CNE/CP no 2, de 9 de junho e a Resolução CNE/CP no 2, de $1^{\circ}$ de julho, que estabelecem as novas DCN para a Formação Inicial em nível superior e para a Formação Continuada. Essas novas DCN não trazem nenhuma novidade em relação à PCC. O primeiro documento apenas explicita, a partir dos Pareceres CNE/CP 28/2001 e CNE/CES 15/2005 discutidos anteriormente, os seguintes pontos: o que é a PCC; qual sua carga horária mínima (400 horas); e qual a diferença entre PCC e estágio supervisionado. Já a Resolução CNE/CP 2/2015 não define o que é a PCC, apenas estabelece sua carga horária e reforça o entendimento de que a PCC na Licenciatura seja concebida não como aplicação de teoria, mas como um espaço de autoria colaborativa que possibilite a criação de um campo de experimentação da docência e da constituição de identidades docentes.

As diretrizes ainda vigentes (Resolução CNE/CP 2/2015) são mais abrangentes que as anteriores, pois não restringe suas diretrizes aos cursos de graduação primeira Licenciatura. O seu artigo nono define que os cursos de formação inicial de professores compreendem: I - cursos de graduação de Licenciatura; II - cursos de formação pedagógica para graduados não licenciados; III - cursos de segunda Licenciatura. Essas diretrizes apresentam em um único documento orientações no que diz respeito a formação inicial, a formação continuada, a valorização profissional, a ampliação da carga horária, determinando o tempo mínimo para integralização do curso que passou a ser no mínimo 8 (oito) semestres ou 4 (quatro) anos e a ampliação da carga-horária mínima de 2800 horas para 3200 horas. 
Outra definição importante para a melhoria da formação de profissionais do magistério, presente na Resolução CNE/CP 2/2015 (Art. 50), consiste na garantia, sem prejuízo de base diversificada, da concepção de educação como processo emancipatório e permanente, bem como pelo reconhecimento da especificidade do trabalho docente, que conduz à práxis como expressão da articulação entre teoria e prática. Assim, ao mesmo tempo em que o licenciando age segundo suas experiências e aprendizagens, deve criar e enfrentar desafios cotidianos e, com base neles, construir seus conhecimentos e saberes, num processo contínuo de fazer e refazer. Para isso, a formação deve privilegiar um sólido conhecimento pedagógico que fundamente sua prática e que o convide à reflexão.

Nesse contexto, entende-se a prática pedagógica como práxis, ou seja, assumir uma postura críticoreflexivo a respeito de suas próprias experiências, concretizada desde o processo de planejamento curricular, planejamento de ensino e/ou planejamento de trabalho até as tomadas de decisão no dia a dia da docência, da orientação e da intervenção. A prática da docência não é um espaço de aplicação de saberes provenientes da teoria, mas de produção de saberes específicos oriundos dessa prática.

Diante do contexto de políticas para a formação de professores no Brasil, apresentamos a seguir o Quadro 1 que mostra as legislações, resoluções e pareceres encontradas que têm relação com as DCN e com as Práticas como Componentes Curriculares.

Quadro 1 - Listagem e Caracterização Resumida das Legislações Referentes à Prática como Componente Curricular (PCC).

\begin{tabular}{|c|c|c|}
\hline Documento & Assunto & PCC \\
\hline $\begin{array}{l}\text { Parecer CNE/CP } \\
\text { n० 9, de } 2001\end{array}$ & $\begin{array}{l}\text { Proposta de Diretrizes Curriculares Nacionais para } \\
\text { a formação de professores da educação básica, em } \\
\text { nível superior, curso de Licenciatura, de graduação } \\
\text { plena. }\end{array}$ & $\begin{array}{l}\text { Explicita uma concepção ampliada } \\
\text { de prática, a partir da PCC. }\end{array}$ \\
\hline $\begin{array}{l}\text { Parecer CNE/CP } \\
\text { n}^{\circ} 28 \text {, de } 2001\end{array}$ & $\begin{array}{l}\text { Dá nova redação ao Parecer CNE/CP no } 21 \text {, de } \\
2001 \text {, o qual propõe a duração e a carga horária } \\
\text { dos cursos de formação de professores da } \\
\text { educação básica. }\end{array}$ & $\begin{array}{l}\text { Propõe a carga horária da PCC } \\
\text { dentro do curso e a diferencia do } \\
\text { estágio supervisionado. }\end{array}$ \\
\hline $\begin{array}{l}\text { Resolução CNE/ } \\
\text { CP no 1, de } \\
2002\end{array}$ & $\begin{array}{l}\text { Institui as DCN para a Formação de Professores da } \\
\text { educação básica, em } \\
\text { nível superior, curso de Licenciatura, de graduação } \\
\text { plena. }\end{array}$ & $\begin{array}{l}\text { Institui a concepção ampliada de } \\
\text { prática, a partir da prática, mais } \\
\text { como componente curricular. }\end{array}$ \\
\hline $\begin{array}{l}\text { Resolução CNE/ } \\
\text { CP no 2, de } \\
2002\end{array}$ & $\begin{array}{l}\text { Institui a duração e a carga horária dos cursos de } \\
\text { Licenciatura, de graduação plena, de formação de } \\
\text { professores da educação básica em nível superior. }\end{array}$ & Institui a carga horária da PCC. \\
\hline $\begin{array}{l}\text { Parecer } \\
\text { CNE/CES } \\
\text { no } 15 \text {, de } 2005\end{array}$ & $\begin{array}{l}\text { Presta esclarecimentos sobre as Resoluções CNE/ } \\
\text { CP n' } 1 \text { e n' } 2 \text {, de } 2002 \text {. }\end{array}$ & $\begin{array}{l}\text { Distingue PCC de prática de } \\
\text { ensino e explicita novamente } \\
\text { sobre a carga horária da PCC. }\end{array}$ \\
\hline $\begin{array}{l}\text { Parecer CNE/CP } \\
\text { n० 2, de } 2015\end{array}$ & $\begin{array}{l}\text { Proposta de Diretrizes Curriculares } \\
\text { Nacionais para a formação inicial } \\
\text { e continuada dos profissionais do } \\
\text { magistério da educação básica. }\end{array}$ & $\begin{array}{l}\text { A partir de legislações anteriores, } \\
\text { principalmente o Parecer CNE/CP no } \\
28 \text {, de } 2001 \text { e o Parecer CNE/CES no } \\
15 \text {, de } 2005 \text {, explicita o papel da } \\
\text { PCC, sua carga horária e } \\
\text { a diferença entre PCC e estágio } \\
\text { supervisionado. }\end{array}$ \\
\hline
\end{tabular}




\begin{tabular}{|c|c|c|}
\hline $\begin{array}{l}\text { Resolução } \\
\text { CNE/CP nº 2, de } \\
2015\end{array}$ & $\begin{array}{l}\text { Define as Diretrizes Curriculares Nacionais para a } \\
\text { formação inicial } \\
\text { em nível superior (cursos de Licenciatura, cursos } \\
\text { de formação } \\
\text { pedagógica para graduados e cursos de segunda } \\
\text { Licenciatura) e para a formação continuada. }\end{array}$ & $\begin{array}{l}\text { Institui a carga horária da PCC para } \\
\text { os cursos de formação de } \\
\text { professores. }\end{array}$ \\
\hline $\begin{array}{l}\text { Parecer CNE/CP } \\
\text { no 22, de } 2019\end{array}$ & $\begin{array}{l}\text { Revisa e atualiza a Resolução CNE/CP } 5 n^{\circ} \\
02 / 2015 \text {, fundamentada no Parecer CNE/CP No } \\
02 / 2015 \text {, levando em conta a legislação vigente, } \\
\text { em especial às Resoluções CNE/CP No 02/2017 e } \\
N^{\circ} 04 / 2018 \text {, definidas com fundamento, } \\
\text { respectivamente, nos Pareceres CNE/CP no } \\
15 / 2017 \text { e } n^{\circ} 15 / 2018 \text { que instituíram e definiram } \\
\text { a implementação da Base Nacional Comum } \\
\text { Curricular (BNCC) para o conjunto de etapas e de } \\
\text { modalidades da Educação Básica. }\end{array}$ & $\begin{array}{l}\text { Mantém a carga horária da PCC } \\
\text { para os cursos de formação de } \\
\text { professores prevista Resolução } \\
\text { CNE/CP n० } 2 \text {, de } 2015 \text {. }\end{array}$ \\
\hline
\end{tabular}

Fonte: Adaptado ${ }^{6}$ de Pereira e Mohr (2017).

\section{NOVA POLÍTICA PARA A FORMAÇÃO DE PROFESSORES NO BRASIL: ANÁLISE COMPARATIVA}

O Parecer CNE/CP no 22, de 2019, chamado de Diretrizes Curriculares Nacionais para a Formação Inicial de Professores para a Educação Básica e Base Nacional Comum para a Formação Inicial de Professores da Educação Básica (BNC-Formação), mantém a carga horária dos cursos de formação inicial de professores para a Educação Básica, em nível superior em 3.200 horas (três mil e duzentas) e a duração de, no mínimo, 08 (oito) semestres ou 04 (quatro) anos. Passa a estabelecer que essa carga horária deve ser dedicada ao desenvolvimento das competências profissionais em três dimensões (Quadro 2): conhecimento, prática e engajamento, assim divididas:

i. Grupo I: 800 (oitocentas) horas para a base comum que compreende os conhecimentos científicos, educacionais e pedagógicos e fundamentam a educação e suas articulações com os sistemas, escolas e práticas educacionais.

ii. Grupo II: 1.600 (mil e seiscentas) horas para a aprendizagem dos conteúdos específicos das áreas, componentes, unidades temáticas e objetos de conhecimento da BNCC e para o domínio pedagógico desses conteúdos.

iii. Grupo III: 800 (oitocentas) horas para a prática pedagógica com a seguinte distribuição: 400 (quatrocentas) horas de estágio e 400 (quatrocentas) horas para os componentes curriculares dos Grupos I e II, das quais: (a) 400 (quatrocentas) horas de estágio supervisionado, em situação real de trabalho em escola, segundo o Projeto Pedagógico do Curso (PPC) da instituição formadora; (b) 400 (quatrocentas) horas de práticas nos componentes curriculares dos Grupos I e II, distribuídas ao longo do curso, desde o seu início, segundo o PPC da instituição formadora.

As DCN de Formação Inicial e Continuada de Professores, no ano de 2015, reafirmam os documentos anteriores nos quais a PCC objetiva aproximar o licenciando, desde o início do curso, da profissão e da prática docente e, seja a partir de situações observadas em sala de aula, na própria escola ou com

\footnotetext{
${ }^{6}$ Foi incluído o Parecer CNE/CP no 22, de 2019.
} 
auxílio de tecnologias da informação, ou transcendendo essa aproximação, envolvendo articulações com órgãos normativos e executivos dos sistemas de ensino.

Nas Diretrizes Curriculares Nacionais e Base Nacional Comum para a Formação Inicial e Continuada de Professores da Educação Básica, no ano de 2019 (Parecer CNE/CP nº 22/2019 e Resolução CNE/CP No 2/2019), determinam no Grupo III, 400 horas de práticas "nos/dos"7 componentes curriculares (dos Grupos I e II), distribuídas ao longo do curso, desde o seu início, segundo o PPC da instituição formadora. Essa determinação, na nossa visão, corresponde a um retrocesso na nova DCN, pois entendemos que prática "nos/dos" componentes curriculares pode ser interpretada apenas como situações que mostrem a sua aplicação (praticismo - campo de aplicação), permitindo uma separação entre a teoria e a prática, tornando-se meramente instrumental. Já prática "como" componente curricular conduz à práxis, ou seja, articulação entre teoria e prática e à exigência de que se leve em conta a realidade dos ambientes das instituições educativas da educação básica e da profissão (DOURADO, 2015).

No Grupo II (1600 horas) a nova DCN prevê que o curso de formação inicial deverá oferecer estudos em currículos referenciados na Base Nacional Comum Curricular (BNCC), metodologias e didática de cada áreas e/ou componentes curriculares. Fazem parte dessa etapa de aprofundamento, entre outras:

i. Domínio dos conhecimentos previstos na BNCC para etapa/área/componente;

ii. Domínio do conteúdo a ser ensinado e seu conhecimento pedagógico;

iii. Desenvolvimento de competências profissionais integradas em três dimensões: conhecimento profissional, prática profissional e engajamento profissional;

iv. Compromisso com a aprendizagem do aluno;

v. Prática efetiva no ambiente educacional;

vi. Criatividade e inovação;

vii. Engajamento com sua formação e seu desenvolvimento profissional.

No Grupo I, as 800 horas previstas devem ser realizadas a partir da integração das três dimensões: conhecimento, prática e engajamento profissionais como organizadores do currículo e os conteúdos segundo as competências e habilidades da Base Nacional Comum Curricular (BNCC) da Educação Básica nas etapas da Educação Infantil, do Ensino Fundamental e do Médio (Quadro 2). Os conhecimentos a serem adquiridos são:

i. Conhecimento dos fundamentos, política e metodologias educacionais;

ii. Sistema de ensino e política pública educacional;

iii. Contexto social e cultural da escola e do aluno - território educativo;

iv. Desenvolvimento cognitivo, físico e socioemocional e aprendizagem por etapa;

\footnotetext{
${ }^{7}$ No Parecer CNE/CP no 22/2019 trata como prática "nos" componentes curriculares e a Resolução CNE/CP No 2/2019 trata como prática "dos" componentes curriculares.
} 
v. Infância e adolescência, a partir da articulação entre as Ciências Humanas - especialmente a Sociologia, a Psicologia e a Filosofia - e as da Saúde;

vi. Linguagens artísticas, arte, cultura e educação em suas formas de expressão - Artes Visuais, Música, Corporais, Literatura e Cultura Digital;

vii. Uso e produção de tecnologia;

viii. Criatividade e inovação;

ix. Planejamento e gestão do ambiente de aprendizagem e da avaliação;

x. Reconhecimento e mediação de conflitos;

xi. Engajamento no desenvolvimento acadêmico e profissional, participação e comprometimento com a escola, relações interpessoais e socioemocionais.

Quadro 2 - Competências específicas das três dimensões conhecimento, prática e engajamento.

\begin{tabular}{|c|c|c|}
\hline \multicolumn{3}{|c|}{ COMPETÊNCIAS ESPECÍFICAS } \\
\hline $\begin{array}{l}\text { CONHECIMENTO } \\
\text { PROFISSIONAL }\end{array}$ & PRÁTICA PROFISSIONAL & ENGAJAMENTO PROFISSIONAL \\
\hline $\begin{array}{l}\text { Dominar os } \begin{array}{l}\text { objetos } \\
\text { conhecimento e } \\
\text { ensiná-los }\end{array} \\
\text { saber como }\end{array}$ & $\begin{array}{l}\text { Planejar as ações de ensino que } \\
\text { resultem em efetivas } \\
\text { aprendizagens }\end{array}$ & $\begin{array}{l}\text { Comprometer-se com o próprio } \\
\text { desenvolvimento profissional }\end{array}$ \\
\hline $\begin{array}{l}\text { Demonstrar conhecimento sobre } \\
\text { os estudantes e como eles } \\
\text { aprendem }\end{array}$ & $\begin{array}{l}\text { Criar e saber gerir ambientes de } \\
\text { aprendizagem }\end{array}$ & $\begin{array}{l}\text { Comprometer-se com a } \\
\text { aprendizagem dos estudantes e } \\
\text { colocar em prática o princípio de } \\
\text { que todos são capazes de aprender }\end{array}$ \\
\hline Reconhecer os contextos & $\begin{array}{l}\text { Avaliar o desenvolvimento do } \\
\text { educando, a aprendizagem e o } \\
\text { ensino }\end{array}$ & $\begin{array}{l}\text { Participar do Projeto Pedagógico da } \\
\text { escola e da construção dos valores } \\
\text { democráticos }\end{array}$ \\
\hline $\begin{array}{ll}\text { Conhecer a } & \text { estrutura e a } \\
\text { governança } & \text { dos sistemas } \\
\text { educacionais } & \end{array}$ & 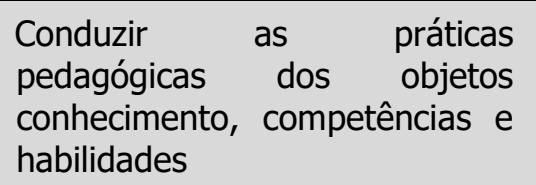 & $\begin{array}{l}\text { Engajar-se profissionalmente, com } \\
\text { as famílias e com a comunidade }\end{array}$ \\
\hline
\end{tabular}

Fonte: Parecer CNE/CP n 22, de 2019

O Parecer CNE/CP n 22/2019 e a Resolução CNE/CP N O 2/2019 trazem as diretrizes para que os cursos de formação de professores sejam mais voltados para a prática de ensino, com a exigência de vivências em escolas de Educação Básica desde o início da graduação, que podem ser observadas nas três dimensões: conhecimento, prática e engajamento profissionais (Grupos I, II e III). Além disso, metade da carga horária (1600 horas) passa a ser destinada à aprendizagem dos conteúdos específicos que os futuros professores irão ensinar, assim como ao domínio pedagógico desses saberes (ou seja, como eles devem ser ensinados - saber ensinado/aprendido). Como podemos observar, a prática nos componentes curriculares não fica restrita ao Grupo III. Nesse cenário, nos parece que o novo documento valoriza demasiadamente a prática em detrimento do saber disciplinar.

De acordo com Pereira e Mohr (2017), a concepção ampliada de prática, objetivada pelas DCN até 2015, tornaram-se importante para valorização da prática profissional docente como espaço de construção de conhecimentos e formação dos licenciandos. O professor não é mais apenas um reprodutor de técnicas e teorias, como se pensava anteriormente, mas sim, alguém que constrói 
saberes e conhecimentos no âmbito do ensino. Além disto, a PCC torna-se importante para favorecer a transposição didática dos conteúdos. A prática que compõe a expressão PCC refere-se à ação ou trabalho docente e pedagógico.

Para Da Silva et al. (2016), a PCC tinha o objetivo de colocar o acadêmico em contato com sua profissão por meio da prática de ensino, do planejamento e elaboração de propostas pedagógicas, da investigação da prática e elaboração de material de divulgação científica. Por suas características de priorizar a transposição didática do conhecimento específico, as disciplinas desse eixo fazem o papel de articulação com as demais, de forma que os acadêmicos perceberem os desafios profissionais de planejamento e execução das atividades didático-pedagógicas.

Conforme Mesquita e Soares (2011), a necessidade de articulação entre teoria e prática emergiu da resolução no 30/74, que criou as chamadas Licenciaturas curtas e estabeleceu que as Licenciaturas Plenas em Física, Química, Biologia e Matemática se transformassem obrigatoriamente, em Licenciaturas em Ciências, com suas respectivas habilitações. Haveria uma parte comum a todas as áreas, uma parte diversificada e a Instrumentação para o Ensino. A Instrumentação para o Ensino trataria da formação pedagógica, e nesse segmento estaria incluída a disciplina de Estágio.

Os textos legais, até 2015, justificam a inserção da PCC nos cursos de formação de professores e de que é necessário superar a dicotomia teoria/prática que durante muito tempo foi mantida por modelos de formação docente fundamentados na racionalidade técnica (modelo criticado nos documentos oficiais como $3+1$ - três anos para formação disciplinar e um ano para a formação pedagógica). Essa justificativa encontra respaldo em Tardif (2018) quando afirma que há uma polarização teoria e prática na formação docente, e por isso admite que é necessário repensar esse modelo, levando em conta os saberes dos professores e as realidades específicas de seu trabalho cotidiano. Entendemos, assim como Tardif (2018), o profissional professor como aquele que produz saberes a partir da sua prática, da sua profissão, das suas experiências e que esses saberes são fundamentais.

Nas DCN de 2019, passamos ter uma nova preocupação, a supervalorização da prática em detrimento da teoria. A prática e a teoria são atividades de natureza diferentes que na docência formam uma relação dialética, isto é, as ações de ensinar levam em conta o pensamento teórico que comanda a intencionalidade da atividade prática. O documento oficial parece evidenciar que existe uma separação crônica entre a teoria e a prática que vai ser corrigido, de acordo com o documento, pela aproximação entre a instituição formadora e a escola. O documento especifica:

A prática pedagógica deve, obrigatoriamente, ser acompanhada por docente da instituição formadora e por um professor experiente na escola onde o estudante a realiza, para o melhor aproveitamento da união entre a teoria e a prática e entre a instituição formadora e o campo de atuação. (CNE/CP, 2019, p. 27)

Acreditamos que as normativas oficiais até 2015, apesar de todos os problemas, alcançaram certo êxito, na medida em que instituiu, pela preocupação com os saberes da formação profissional, mudanças curriculares com a ampliação do tempo dedicado aos estudos pedagógicos na carga horária total dos cursos de formação de professores. Nesse sentido, as PCC deviam estar articuladas de forma coerente com o curso e ser distribuídas entre as disciplinas específicas e as de formação pedagógica. A formação dos profissionais para o magistério da Educação Básica, deve procurar evitar a tradicional fragmentação dos saberes da docência e a dicotomia teoria/prática.

No Quadro 3 apresentamos um comparativo da carga horária indicada nos documentos. 
Quadro 3 - Quadro comparativo da Carga Horária a partir das Diretrizes Curriculares de Formação de Professores de 2002, 2015 e 2019.

\begin{tabular}{|c|c|c|c|}
\hline & $\begin{array}{c}\text { Resolução CNE/CP } \\
\text { n.2, de } 19 \text { de } \\
\text { fevereiro de } 2002 \text {. }\end{array}$ & $\begin{array}{l}\text { Resolução CNE/CP no 2, } \\
\text { de } 1^{\circ} \text { de julho de } 2015 .\end{array}$ & $\begin{array}{l}\text { Resolução CNE/CP N } \circ 2 \text {, de } \\
20 \text { de dezembro de } 2019 \text {. }\end{array}$ \\
\hline $\begin{array}{c}\text { Carga } \\
\text { Horária das } \\
\text { Licenciaturas }\end{array}$ & $\begin{array}{l}\text { Art. } 10 \text { A carga horária } \\
\text { dos cursos de Formação } \\
\text { de Professores da } \\
\text { Educação Básica, em } \\
\text { nível superior, em curso } \\
\text { de Licenciatura, de } \\
\text { graduação plena, será } \\
\text { efetivada mediante a } \\
\text { integralização de, no } \\
\text { mínimo, } 2800 \text { (duas mil } \\
\text { e oitocentas) horas. }\end{array}$ & $\begin{array}{l}\text { Art. 13. } \S 10 \text { Os cursos de } \\
\text { que trata o caput terão, no } \\
\text { mínimo, } 3.200 \text { (três mil e } \\
\text { duzentas) horas de efetivo } \\
\text { trabalho acadêmico. }\end{array}$ & $\begin{array}{l}\text { Art. 10. estabelece que cursos de } \\
\text { formação inicial de professores } \\
\text { para a Educação Básica, em } \\
\text { nível superior, é constituída de } \\
3.200 \text { (três mil e duzentas) horas } \\
\text { de efetivo trabalho acadêmico. }\end{array}$ \\
\hline $\begin{array}{c}\text { Distribuição } \\
\text { da Carga } \\
\text { Horária }\end{array}$ & 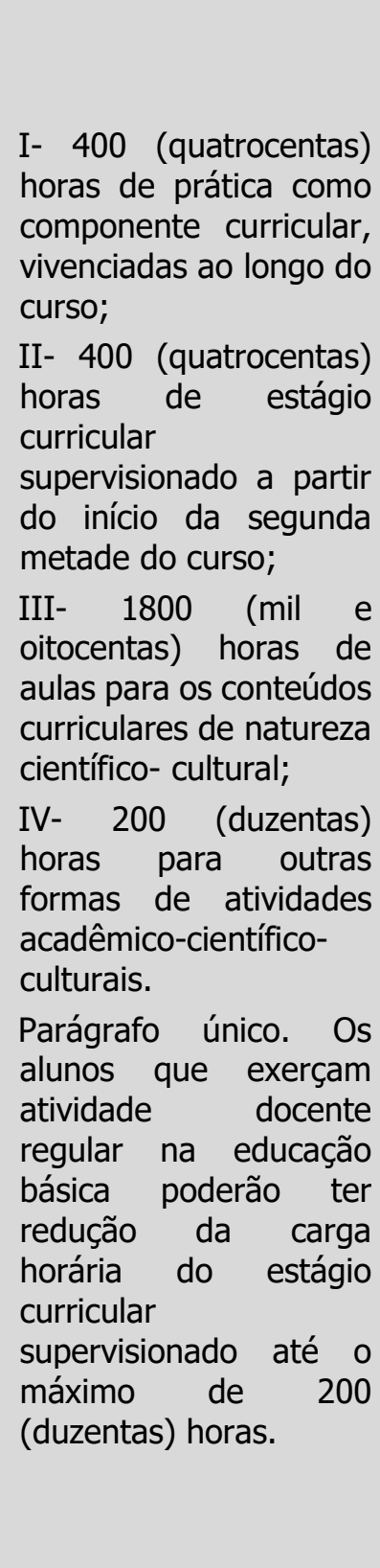 & $\begin{array}{l}\text { I- } 400 \text { (quatrocentas) horas } \\
\text { de prática como } \\
\text { componente curricular, } \\
\text { distribuídas ao longo do } \\
\text { processo formativo; } \\
\text { II- } 400 \text { (quatrocentas) } \\
\text { horas dedicadas ao estágio } \\
\text { supervisionado, na área de } \\
\text { formação e atuação na } \\
\text { educação básica, } \\
\text { contemplando também } \\
\text { outras áreas específicas, se } \\
\text { forem o caso, conforme o } \\
\text { projeto de curso da } \\
\text { instituição; } \\
\text { III- pelo menos } 2.200 \text { (duas } \\
\text { mil e duzentas) horas } \\
\text { dedicadas às atividades } \\
\text { formativas estruturadas } \\
\text { pelos núcleos definidos nos } \\
\text { incisos I e II do artigo } 12 \\
\text { desta Resolução, conforme } \\
\text { o projeto de curso da } \\
\text { instituição; } \\
\text { IV- } 200 \text { (duzentas) horas de } \\
\text { atividades teórico-práticas } \\
\text { de aprofundamento em } \\
\text { áreas específicas de } \\
\text { interesse dos estudantes, } \\
\text { conforme núcleo definido } \\
\text { no inciso III do artigo } 12 \\
\text { desta Resolução, por meio } \\
\text { da iniciação científica, da } \\
\text { iniciação à docência, da } \\
\text { extensão e da monitoria, } \\
\text { entre outras, consoante o } \\
\text { projeto de curso da } \\
\text { instituição. }\end{array}$ & $\begin{array}{l}\text { I- Grupo I: } 800 \text { (oitocentas) } \\
\text { horas para a base comum que } \\
\text { compreende os conhecimentos } \\
\text { científicos, educacionais e } \\
\text { pedagógicos e fundamentam a } \\
\text { educação e suas articulações } \\
\text { com os sistemas, escolas e } \\
\text { práticas educacionais; } \\
\text { II- Grupo II: 1.600 (mil e } \\
\text { seiscentas) horas para a } \\
\text { aprendizagem dos conteúdos } \\
\text { específicos das áreas, } \\
\text { componentes, unidades } \\
\text { temáticas e objetos de } \\
\text { conhecimento da BNCC e para o } \\
\text { domínio pedagógico desses } \\
\text { conteúdos. } \\
\text { III- Grupo III: 800 (oitocentas) } \\
\text { horas para a prática pedagógica } \\
\text { com a seguinte distribuição: } 400 \\
\text { (quatrocentas) horas de estágio } \\
\text { e } 400 \text { (quatrocentas) horas para } \\
\text { os componentes curriculares dos } \\
\text { Grupos I e II, das quais: (a) } 400 \\
\text { (quatrocentas) horas de estágio } \\
\text { supervisionado, em situação real } \\
\text { de trabalho em escola, segundo } \\
\text { o Projeto Pedagógico do Curso } \\
\text { (PPC) da instituição formadora; } \\
\text { (b) } 400 \text { (quatrocentas) horas de } \\
\text { práticas dos componentes } \\
\text { curriculares dos Grupos I e II, } \\
\text { distribuídas ao longo do curso, } \\
\text { desde o seu início, segundo o } \\
\text { PPC da instituição formadora. }\end{array}$ \\
\hline
\end{tabular}

Fonte: Elaborado pelos autores. 


\section{CONSIDERAÇÕES FINAIS}

A formação de professores, sob a perspectiva das novas DCN (BNC-Formação), parece assumir um caráter restrito e instrumental do docente, com ênfase na prática e que fica dissociada da teoria. Consideramos que colocar apenas a BNCC no centro formação de professores constitui um reducionismo, principalmente porque não prevê um perfil profissional voltado para o desenvolvimento de sua autonomia com capacidade de tomar decisões e dar respostas aos desafios que encontra na escola. Ao supervalorizar a dimensão prática em detrimento da dimensão teórica a DCN, reduz os professores a meros executores da BNCC, ou seja, apenas executar um currículo padronizado, desconsiderando que o Brasil é um país federativo e cabe à União, aos Estados, ao Distrito Federal e aos Municípios, em regime de colaboração, organizar seus próprios sistemas educativos.

É importante não perdermos de vista que a docência não se reduz à prática de ensino, ao saber fazer. A forma de atuação do professor é caracterizada como uma prática educativa com várias dimensões, saberes profissionais, saberes disciplinares, saberes curriculares e saberes experienciais. Desse modo, os processos formativos não podem se limitar aos conteúdos relacionados ao saber fazer.

A nova DCN apresenta um caráter tecnicista, reducionista e praticista, pois se referencia quase que exclusivamente nas determinações da BNCC para a Educação Básica e retira das Instituições de Ensino Superior a possibilidade de formação solidamente constituída no campo das Ciências da Educação e das Ciências Pedagógicas, ignorando a abrangência da formação de um licenciado na área de Ciências da Natureza (Licenciaturas em Física, Química e Biologia) para atuar nas diversas modalidades de ensino (Básica, Tecnológica e Superior) reduzindo o foco da sua formação para a futura atuação apenas na Educação Básica.

Outro problema está nas concepções da nova base ao pensar uma formação padronizada para a maioria dos professores em um país muito desigual e diverso, desconsiderando-se, desta forma, o contexto dos professores. Também não se identifica na BNC-Formação, competências para o professor ser mais autônomo em relação às decisões curriculares, para ser reflexivo, crítico e agir como um pesquisador, com o objetivo de estar em constante revisão da sua própria prática e ter um olhar investigativo sobre todo o processo de formação.

Por fim, é importante salientar que a nova Resolução, antes de qualquer coisa, confirma o movimento de alinhamento e estreitamento curricular da formação de professores à Reforma do Ensino Médio (Lei n.13.415, 2017), à BNCC da Educação Infantil e Ensino Fundamental (2017) e à BNCC do Ensino Médio (2018), assim como dá outro rumo para aquilo que vinha sendo entendido e construído como Diretrizes para a formação de professores, a partir das Diretrizes Curriculares Nacionais para a formação inicial e continuada dos profissionais do magistério da Educação Básica de 2015 (Resolução CNE/CP no 2, de 2015).

\section{REFERÊNCIAS}

BRASIL. Lei no 9.394, de 20 de dezembro de 1996. Lei de Diretrizes e Bases da Educação Nacional (LDBEN). Estabelece as Diretrizes e bases da Educação Nacional. Brasília, DF. Disponível em: <http://www.planalto.gov.br/ccivil_03/leis/L9394.htm>. Acesso em:10 outubro. 2019. 
BRASIL. Resolução no 30, de 11 de julho de 1974. Fixa os mínimos de conteúdo e duração a observar na organização do curso de licenciatura em Ciências. CFE. Documenta, Brasília, (164): 509-11, jul. 1974.

BRASIL. Parecer CNE/CP no 9, de 8 de maio de 2001a. Proposta de Diretrizes Curriculares Nacionais para a Formação de Professores da Educação Básica, em nível superior, curso de licenciatura, de graduação plena. Brasília, DF, 2001a. Disponível em: <http://portal.mec.gov. br/cne/arquivos/pdf/009.pdf>. Acesso em: 18 outubro. 2019.

BRASIL. Parecer CNE/CP no 28, de 2 de outubro de 2001b. Dá nova redação ao Parecer CNE/CP 21/2001, de 6 de agosto de 2001, e discorre sobre a duração e a carga horária dos cursos de Formação de Professores da Educação Básica, em nível superior, curso de licenciatura, de graduação plena. Brasília, DF, 2001b. Disponível em:

<http://portal.mec.gov.br/cne/arquivos/pdf/028.pdf>. Acesso em: 12 outubro. 2019.

BRASIL. Resolução CNE/CP no 1, de 18 de fevereiro de 2002a. Institui Diretrizes Curriculares Nacionais para a Formação de Professores da Educação Básica, em nível superior. Brasília, DF, 2002a. Disponível em: <portal.mec.gov.br/cne/arquivos/pdf/rcp01_02.pd>. Acesso em:12 outubro. 2019.

BRASIL. Resolução CNE/CP nº 2, de 19 de fevereiro de 2002b. Institui a duração e a carga horária dos cursos de Formação de Professores da Educação Básica, em nível superior. Brasília, DF, 2002b. Disponível em: <http://portal.mec.gov.br/cne/arquivos/pdf/CP022002.pdf>.Acesso em: 12 outubro. 2019.

BRASIL. Parecer CNE/CES no 15, de 2 de fevereiro 2005. Solicitação de esclarecimento sobre as Resoluções CNE/CP n's 1 e 2/2002, que instituem Diretrizes Curriculares Nacionais para a Formação de Professores da Educação Básica, em nível superior. Brasília, DF. Disponível em: <http://portal.mec.gov.br/cne/arquivos/pdf/pces0015_05.pdf. >. Acesso em: 10 outubro. 2015.

BRASIL. Parecer CNE/CP nº 2, de 9 de junho de 2015a. Define Diretrizes Curriculares Nacionais para Formação Inicial e Continuada dos Profissionais do Magistério da Educação Básica. Brasília, DF, 2015a. Disponível em:

$<$ http://portal.mec.gov.br/index.php?option=com_docman\&view=download\&alias=17625-parecercne-cp-2-2015-aprovado-9-junho-2015\&category_slug=junho-2015-pdf\&Itemid=30192>. Acesso em: 15 out. 2019.

BRASIL. Resolução CNE/CP no 2, de $1^{\circ}$ de julho de 2015b. Define as Diretrizes Curriculares Nacionais para a Formação Inicial, em nível superior (cursos de licenciatura, cursos de formação pedagógica para graduados e cursos de segunda licenciatura) e para a formação continuada. Brasília, DF, 2015b. Disponível em:

<http://portal.mec.gov.br/index.php?option=com_docman\&view=download\&alias=17719-rescnecp-002-03072015\&category_slug=julho-2015-pdf\&Itemid=30192>. Acesso em: 15 out. 2019.

BRASIL. Parecer CNE/CP no 22, de 7 de novembro de 2019. Diretrizes Curriculares Nacionais para a Formação Inicial de Professores para a Educação Básica e Base Nacional Comum para a Formação Inicial de Professores da Educação Básica (BNC-Formação). Disponível em: http://portal.mec.gov.br/index.php?option=com docman\&view=download\&alias=133091-pcp02219-3\&category slug=dezembro-2019-pdf\&Itemid=30192. Acesso em: 12 de dezembro de 2019.

BRASIL. Resolução CNE/CP no 2, de 20 de dezembro de 2019. Diretrizes Curriculares Nacionais para a Formação Inicial de Professores para a Educação Básica e institui a Base Nacional Comum para a Formação Inicial de Professores da Educação Básica (BNC-Formação). 
Disponível em: < http://portal.mec.gov.br/docman/dezembro-2019-pdf/135951-rcp002-19/file> . Acesso em: 29 dezembro 2019.

DA SILVA, S. L. R.; BRINATTI, A. M.; DE ANDRADE, A. V. C.; DA SILVA, J. B. A prática como componente curricular na licenciatura em física da Universidade Estadual de Ponta Grossa. Revista Tecné, Episteme y Didaxis: TED. Número Extraordinario, Bogotá, 2016.

DOURADO, L. F. Diretrizes Curriculares Nacionais para a formação inicial e continuada dos profissionais do magistério da Educação Básica: Concepções e desafios. Educação e Sociedade, v. $36, n^{0} .131,2015$.

MESQUITA, N. A.; SOARES, M. H. F. B. Aspectos históricos dos cursos de licenciatura em química no brasil nas décadas de 1930 a 1980. Química Nova, Vol. 34, No. 1, 165-174, 2011.

TARDIF, M. Saberes profissionais dos professores e conhecimentos universitários: elementos para uma epistemologia da prática profissional dos professores e suas consequências em relação à formação para o magistério. Rev. Bras. de Educação, Rio de Janeiro, n. 13, p. 1-20, jan./fev./mar./abr. 2000.

TARDIF, M. Saberes Docentes e Formação profissional. 17. ed. Petrópolis: Vozes, 2018.

PEREIRA, B.; MOHR A. Origem e Contornos da Prática como Componente Curricular. In: MOHR A.; Wielewicki, H. de G. Prática como componente curricular: que novidade é essa 15 anos depois? Florianópolis: NUP/CED/UFSC, 2017.

PIMENTA, Selma G.; LIMA, Maria S. L. Estágios supervisionados e o Programa Institucional de Bolsa de Iniciação à Docência: duas faces da mesma moeda?. Revista Brasileira de Educação. v. 24 e240001, 2019.

SOUZA NETO, S. de; SILVA, V. P. da. Prática como Componente Curricular: questões e reflexões. Rev. Diálogo Educ., Curitiba, v. 14, n. 43. 